\title{
VIABILIDADE DO LODO DE ESGOTO NA AGRICULTURA
}

\section{Guilherme Rodrigues Alves Mesquita}

Bacharel em Engenharia Ambiental e Sanitária/Universidade Estácio de Sá/UNESA/RJ. guilherme.ram@live.com

\section{Jessyana Rangel Von Randow}

Bacharel em Engenharia Ambiental e Sanitária/Universidade Estácio de Sá/UNESA/RJ. jessyana_rangel@hotmail.com

\section{Raquel Lima Oliveira}

Doutorado em Química pela Universidade Federal Fluminense.

quell_2008@yahoo.com.br

\author{
Marcela Vicente Vieira Andrade Gonçalves \\ Doutorado em Biologia pela Universidade Federal do Rio de Janeiro. \\ marcelandrade14@yahoo.com.br
}

\section{RESUMO}

Este estudo identificou através de uma pesquisa exploratória sobre os fatores que viabilizam o lodo de esgoto como resíduo de elevado potencial para o cultivo de certas culturas. Entre outras fontes complementares de conteúdo, o procedimento de pesquisa bibliográfico buscou duas obras, de autores distintos, que apontavam para três fatores (qualidade do resíduo, tipo de solo da área de aplicação e cultura) como condicionantes da destinação do lodo para reciclagem agrícola. Quando o lodo de esgoto é tratado e processado, este recebe o nome de biossólido. Esta pesquisa abordou as etapas de gerenciamento do lodo nas estações de tratamento de esgoto, sua aplicação na agricultura e os riscos associados ao seu emprego nesta. No entanto, o resultado deste estudo mostrou que o lodo e seus derivados têm aplicabilidade na agricultura caso cumpra os requisitos mínimos exigidos de qualidade física, química, biológica e de patógenos referenciados pela Resolução CONAMA n 375/06. Esse trabalho foi realizado com o apoio da Universidade Estácio de Sá.

Palavras-chave: Lodo; Esgoto; Reciclagem agrícola.

\begin{abstract}
This study identified through an exploratory research on the factors that enable the sewage sludge as high residue potential for the cultivation of certain crops. Among other complementary sources of content, the bibliographic search procedure sought two works of different authors, which pointed to three factors (quality of the residue, soil type of application area and culture) as conditions of agricultural recycling sludge disposal. When sewage sludge is treated and processed, this gets its name from biosolids. This research addressed the steps of management of sludge in sewage treatment plants, its application in agriculture and the risks associated with this job. However, the result of this study showed that the sludge and its derivatives have applicability in agriculture case meets the minimum requirements required of physical quality, chemistry, and biological pathogens referenced by CONAMA's Resolution $n^{\circ} 375 / 06$. This work was supported by University Estacio de Sa.
\end{abstract}

Keywords: Sludge; Sewer; Agricultural recycling.

Persp. Online: exatas \& eng., Campos dos Goytacazes, 17 (07) 80 - 87 - 2017

seer.perspectivasonline.com.br 


\section{INTRODUÇÃO}

Com destaque para ausência e deficiência do sistema de esgotamentos sanitários em muitos municípios e os problemas relacionados ao lançamento desses efluentes in natura nos corpos hídricos, Rodrigues e Silva (2011) apontam a necessidade de ampliar as redes de coleta e o tratamento daqueles, para $o$ atendimento aos serviços de saneamento.

Os tratamentos dessas águas residuárias tornam-se essenciais para a diminuição da poluição ambiental, por isso seu processamento se dá em quatro níveis (preliminar, primário, secundário e terciário) em uma estação de tratamento de esgoto (BERNARDES, 2004). A implantação dessas etapas depende da eficiência requerida de projeto da estação e da capacidade do corpo hídrico receptor de depurar as águas (BRASIL, 2008).

Para cada processo de tratamento de esgoto serão gerados resíduos sólidos (material gradeado, areia, escuma e lodo) de características e composições diferentes que deverão ser submetidos a procedimentos específicos de reutilização ou disposição final, seja para uso benéfico ou não. O lodo é um desses resíduos proveniente dos tratamentos primário, secundário e terciário (MATTA, 2011; GONÇALVES; SPERLING, 2001; ANDREOLI et al., 2001b).

O tipo e intensidade do tratamento das águas residuárias influenciam nas características do lodo gerado e na forma de disposição final deste; e, por conseguinte, a escolha entre descarte ou uso benéfico do biossólido determinará a relevância entre um tipo de tratamento do lodo ou outro (ANDREOLI et al., 2001b).

O tratamento do lodo de esgoto objetiva a redução do volume, do teor de matéria orgânica, da instabilidade biológica, além de minimizar a presença de patógenos (ANDREOLI et al., 2001b). Para alcançar estes objetivos, o processamento do lodo usualmente inclui um ou mais tratamentos para retirada dessas características indesejáveis. Os objetivos devem estar aliados com a quantidade de lodo a ser tratada e a integração dos processos de tratamento, pois compatibilizam com as formas de destinação final do lodo (disposição oceânica, aterros sanitários, incineração, reaproveitamento industrial, reciclagem agrícola e na recuperação de solos degradados) (CASSINI et al., 2003; ANDREOLI; SPERLING, 2001; FERNANDES; LUDUVICE, 2001).

Segundo Gonçalves e Sperling (2001), dependendo do destino final que se deseja dar ao lodo, as principais etapas de trato comumente adotadas são: Estabilização; Desidratação e Higienização.

O objetivo geral deste projeto de pesquisa é demonstrar a viabilidade do uso de biossólidos na agricultura como insumo, causando os menores danos possíveis ao meio ambiente e à saúde humana, relacionando-os com a Política Nacional de Resíduos Sólidos e a Resolução CONAMA 357/2006. Esta institui a responsabilidade da ETE como geradora de resíduos urbanos e incentiva a reciclagem destes. Já a Resolução 375 dá providências sobre os requisitos mínimos de qualidade ambiental, sanitária e agronômica para o uso dos biossólidos na agricultura (BRASIL, 2006).

O lodo quando tratado e processado obtêm características permissíveis para o uso agrícola de maneira ambientalmente segura. De acordo com Bettiol e Camargo (2000), o uso agrícola do lodo de esgoto como adubo orgânico é considerado hoje alternativa promissora de disposição final desse resíduo. Por ser rico em matéria orgânica e em macro e micronutrientes (como o nitrogênio, fósforo, potássio, entre outros), para as plantas recomenda-se sua aplicação como fertilizante e/ou condicionador de solo.

Persp. Online: exatas \& eng., Campos dos Goytacazes, 17 (07) 80 - 87 - 2017

seer.perspectivasonline.com.br 
A disposição dos biossólidos para recuperação de áreas degradadas e a reciclagem agrícola são as medidas mais ambientalmente aconselháveis para o lodo, tendo em vista a viabilidade da reciclagem dos nutrientes e a promoção de melhorias físicas na estruturação do solo (SANTOS, 2001; GODOY, 2013).

Costa et al. (1999) e Andreoli et al. (2001b) marcam os biossólidos como sendo ambiental e economicamente viáveis na reciclagem agrícola pela análise de três critérios: a qualidade do lodo, o tipo de solo da área de aplicação e o tipo de cultura.

Andreoli et al. (2001b, p. 333) fazem uma análise mais abrangente da viabilidade dos biossólidos, acrescentando os riscos associados a estes critérios de disposição benéfica. Os riscos estão relacionados com o conteúdo de metais pesados, o perfil sanitário, a estabilidade do material, os poluentes orgânicos persistentes, o conteúdo de nitrogênio e à integração do lodo com o meio ambiente.

\subsection{Objetivos}

\subsubsection{Objetivo Geral}

A reciclagem agrícola como método de disposição final para lodos de esgoto demanda responsabilidade de seus gestores e exige análise da qualidade do lodo, do solo das áreas de aplicação e do tipo de cultura. Logo, o objetivo geral desta pesquisa é demonstrar a viabilidade do uso de biossólidos na agricultura como insumo, causando os menores danos possíveis ao meio ambiente e à saúde humana.

\subsubsection{Objetivos Específicos}

O tema será desdobrado em objetivos específicos que provam a viabilidade desse resíduo urbano, que são:

a) Identificar os pontos de origem do lodo em uma ETE;

b) Destacar e conceituar a importância das etapas de tratamento do lodo;

c) Citar a Resolução CONAMA 375/2006 como norma regulamentadora para biossólidos;

d) Fundamentar e discutir os três fatores que garantem a viabilidade do lodo como insumo agrícola.

\section{METODOLOGIA}

Este é um estudo descritivo que utilizou recursos de pesquisa exploratória de levantamento bibliográfico, como as publicações de livros, os artigos acadêmicos, a web e os periódicos científicos. Estas fontes bibliográficas sustentam este projeto de pesquisa sobre a viabilidade ambiental, econômica e agronômica do uso do lodo de esgotamento sanitário como insumo agrícola, com base na legislação (Resolução CONAMA 375/2006) que dá critérios e providências para este tipo de destinação final do lodo para uso benéfico.

Persp. Online: exatas \& eng., Campos dos Goytacazes, 17 (07) 80 - 87 - 2017

seer.perspectivasonline.com.br 


\section{RESULTADOS E DISCUSSÕES}

O lodo gerado nas estações de tratamento de esgoto no Brasil é tratado para ser descartado diretamente em aterros sanitários. Este tipo de descarte está em decaimento, pois as exigências ambientais e sanitárias estão cada vez maiores com estímulo às políticas sustentáveis (ANDREOLI et al., 2001a).As alternativas para a disposição final do lodo de esgoto é normalmente complexa por envolver aspectos técnicos, econômicos, ambientais e legais, que ultrapassam os limites das estações de tratamento.

Em sua composição, o lodo contém microrganismos patogênicos, metais pesados e outros compostos tóxicos, mesmo após o processo de tratamento, o lodo quando disposto de maneira inadequada, pode trazer danos ao meio ambiente e a saúde humana.

No tratamento de águas residuárias o tipo e intensidade do tratamento influenciam nas características do lodo gerado e na forma de disposição final deste. A escolha entre descarte ou uso benéfico do biossólido determinará a relevância entre um tipo de tratamento do lodo ou outro (ANDREOLI et al., 2001a; ANDREOLI et al., 2001b).

Andreoli et al. (2001a, p.302) determina que antes da avaliação para escolha do destino final do lodo, os gestores precisam conhecer "as características da própria estação, a quantidade e o tipo de lodo, até os sistemas de estabilização, desaguamento, higienização, estocagem e manuseio do lodo".

Costaet al. (1999) e Andreoli et al. (2001b) marcam os biossólidos como sendo ambiental e economicamente viáveis na reciclagem agrícola pela análise de três critérios: a qualidade do lodo, o tipo de solo da área de aplicação e o tipo de cultura.

Os parâmetros agronômicos são garantidos pela disponibilidade de quantidades variáveis de nutrientes ( $4 \%$ de nitrogênio, $2 \%$ de fósforo, $0,3 \%$ de potássio, e outros macro e micro nutrientes) que fornecem a quantidade necessária exigida para cada tipo de planta. A complementação de nutrientes nas culturas deve ser controlada pelas taxas de aplicação, uma vez que o seu uso indiscriminado pode causar efeitos tóxicos (ANDREOLI et al. 2001b; BETTIOL; CAMARGO, 2006; JORDÃO; PÊSSOA, 2011; SANTOS, 2001).

Santos (2009, p. 24 apud TSUTIYA, 2001) ressalta que "a composição do lodo de esgoto, em termos de metais pesados, varia com o nível socioeconômico e cultural da população". Os metais pesados são potencialmente tóxicos quando estão acima da concentração limite, por isso há a preocupação da mobilidade destes para o solo. Jordão e Pessoa (2011) pontuam que os biossólidos podem alterar o pH do solo e consequentemente a influência de absorção dos metais pesados pelas plantas.

A sanidade dos biossólidos está ligada diretamente ao perfil de microrganismos patógenos humanos presentes (bactérias, vírus, fungos, protozoários e helmintos) e poluentes orgânicos persistentes (BETTIOL; CAMARGO, 2006).

São indispensáveis para análise microbiológica: o limite de ovos de helmintos viáveis, as densidades de coliformes fecais por grama de sólidos secos e de Salmonella por 4 gramas de sólidos secos, e a contagem de bacteriófagos (BRASIL, 2006; SANTOS, 2001 apud USEPA). Jordão e Pessôa (2011) apontam a classificação dos biossólidos com base na densidade de patógenos presentes no lodo de esgoto proposta pela Resolução CONAMA 375.

Já os poluentes orgânicos persistentes, Andreoli et al (2001b, p.337) apontam que alguns são dissipados no decorrer do tratamento biológico do esgoto e outros são efetivamente reduzidos, não obstante, uma parcela desses poluentes alcança o adensamento do lodo, contaminando-o.

Persp. Online: exatas \& eng., Campos dos Goytacazes, 17 (07) 80 - 87 - 2017

seer.perspectivasonline.com.br 
O grau de estabilidade do biossólido é avaliado pela relação de sólidos voláteis e sólidos totais que deve ser inferior a 0,7 (JORDÃO; PESSÔA, 2011). A estabilidade do material pode também ser medida pela predisposição de atrair vetores e a emitir odores nas áreas de estocagem e aplicação no solo (USEPA, 2000).

A capacidade do solo de incorporar o biossólido promove, segundo Andreoli et al. (2001b, p. 339), "a rápida atividade biológica e a ciclagem de nutrientes, matéria orgânica e outros componentes sem oferecer riscos ao ambiente, à saúde e ao potencial produtivo do solo". Essa capacidade pode ser avaliada pelos parâmetros de: profundidade, textura, erosão, relevo, lençol freático, drenagem, hidromorfismo, declividade e estrutura.

A viabilidade de biossólidos está diretamente relacionada às culturas exploradas. A Resolução CONAMA 375 dá providências sobre o uso e manejo dos biossólidos em certas culturas, causando o menor impacto negativo possível (ANDREOLI et al., 2001b; BRASIL, 2006). A Tabela 1 mostra as recomendações e restrições desta norma para os tipos de culturas.

Tabela 1: Espécies indicadas e restrições para cultivo com biossólidos.

\begin{tabular}{|c|l|}
\hline \multicolumn{1}{|c|}{ Item } & \multicolumn{1}{c|}{ Especificação } \\
\hline \multirow{2}{*}{ Recomendações } & $\begin{array}{l}\text { a) Grandes culturas, cujos produtos são industrializados ou não consumidos in } \\
\text { natura; } \\
\text { b) Reflorestamento e manejo florestal; } \\
\text { c) Fruticultura, em covas ou incorporação antes da frutificação anualmente; } \\
\text { d) Áreas degradadas, em dosagens que respeitem o acúmulo máximo de metais no } \\
\text { solo; } \\
\text { d) Grama, aplicação na implantação do gramado com incorporação; } \\
\text { e) Área de disposição dedicada, todos os constituintes do lodo serão mantidos dentro } \\
\text { da área (opção menos desejada). }\end{array}$ \\
\hline Restrições & $\begin{array}{l}\text { a) Não pode ser utilizado em olerícolas, culturas de contato primário para } \\
\text { piscicultura; } \\
\text { b) O cultivo de olerícolas e culturas de contato primário não poderá ser efetuado num } \\
\text { prazo de 12 meses após a incorporação do lodo na área; } \\
\text { c) Pastagens: entrada de animais após um período de 2 meses após incorporado. }\end{array}$ \\
\hline
\end{tabular}

Fonte: adaptado de Andreoli et al., 2001b, p.352 apud Fernandes (1999).

Persp. Online: exatas \& eng., Campos dos Goytacazes, 17 (07) 80 - 87 - 2017

seer.perspectivasonline.com.br 


\section{CONCLUSÕES}

Este estudo demonstrou alternativas seguras para o descarte do lodo, após de tratado e processado. As unidades das estações de tratamento de esgoto precisam adequar os processos de tratamento (estabilização, remoção de umidade e higienização) garantindo a qualidade do produto e a segurança no reuso, a fim de produzir biossólidos viáveis para a agricultura.

Para a reciclagem agrícola do lodo devem ser considerados alguns aspectos, tais como: condições do solo para o uso do lodo de esgoto, qualidade do lodo e cultura agrícola recomendada. O estudo concluiu que o lodo, como biossólido, só será viável caso apresente as características especificadas pela norma que o regulamenta, assim como um plano de gerenciamento e monitoramento que avalie a produção do resíduo, os tipos de tratamento empregados, uso e manuseio dos biossólidos das unidades até os campos de cultivo.

\section{REFERÊNCIAS BIBLIOGRÁFICAS}

ANDREOLI, C. V.; et al. Avaliação de alternativas e gerenciamento do lodo na ETE. In: ANDREOLI, C. V.; FERNANDES, F.; SPERLING, M. (Org.) Belo Horizonte: Departamento de Engenharia Sanitária e Ambiental - UFMG; Companhia de Saneamento do Paraná, 2001a.cap.7. (Princípios do tratamento biológico de águas residuárias, 6).

ANDREOLI, C. V.; et al. Disposição do lodo no solo. In: ANDREOLI, C. V.; FERNANDES, F.; SPERLING, M. (Org.). Lodos de esgoto: tratamento e disposição final. Belo Horizonte: Departamento de Engenharia Sanitária e Ambiental - UFMG; Companhia de Saneamento do Paraná, 2001b. cap.8, p. 319396. (Princípios do tratamento biológico de águas residuárias, 6).

ANDREOLI, C. V.; SPERLING, M. Introdução. In: ANDREOLI, C. V.; FERNANDES, F.; SPERLING, M. (Org.). Lodos de esgoto: tratamento e disposição final. Belo Horizonte: Departamento de Engenharia Sanitária e Ambiental - UFMG; Companhia de Saneamento do Paraná, 2001. cap.1, p. 13-16. (Princípios do tratamento biológico de águas residuárias, 6).

BERNARDES, R. S. Esgotos combinados e controle da poluição: estratégias para planejamento do tratamento da mistura de esgotos sanitários e águas pluviais. Brasília: CAIXA, 2004. cap. 2 e 4.

BETTIOL,W.; CAMARGO, O. A. A disposição de lodo de esgoto em solo agrícola. In: BETTIOL,W.; CAMARGO, O. A. Lodo de esgoto: impactos ambientais na agricultura. 1 ed. Jaguariúna: Embrapa Meio Ambiente, 2006. cap. 2, p. 25-35.

BETTIOL, W.;CAMARGO, O. A.Agricultura: opção animadora para a utilização de lodo de esgoto. O Agronômico, São Paulo, n.52, p.13-16, 2000. Disponível em: <http://www.iac.sp.gov.br/publicacoes> Acesso em: 22 maio 2015.

BRASIL. Ministério das Cidades. Secretaria Nacional de Saneamento Ambiental. Transversal: lodo gerado durante o tratamento de água e esgoto: guia do profissional em treinamento: nível 2. Secretaria Nacional de Saneamento Ambiental (org.). Brasília: Ministério das Cidades, 2008. 90 p.

Persp. Online: exatas \& eng., Campos dos Goytacazes, 17 (07) 80 - 87 - 2017

seer.perspectivasonline.com.br 
BRASIL. Ministério do Meio Ambiente. Conselho Nacional do Meio Ambiente. Resolução n 375 de 29 de agosto de 2006. Brasília: Governo Federal, 2006. Disponível em: <http://www.mma.gov.br>. Acesso em: 02 mar. 2015.

CASSINI, S. T.; PINTO, M. T.; VAZOLLER, R. F. Introdução. In: CASSINI, S. T. Digestão anaeróbia de resíduos sólidos orgânicos e aproveitamento do biogás. Rio de Janeiro: ABES, RiMa, 2003. 1-10 p. Projeto PROSAB. Disponível em: <http://migre.me/qmaGH> Acesso em: 15 abr. 2015.

COSTA, A. N.; et al. Reciclagem do lodo de lagoas na agricultura. In: GONÇALVES, R. F. Gerenciamento do lodo de lagoas de estabilização não mecanizadas. Espírito Santo: Universidade Federal do Espírito Santo, 1999. p. 60-67. Disponível em: <http://migre.me/qm9GC> Acesso em: 9 mar. 2015.

FERNANDES, F.; LUDUVICE, M. Principais tipos de transformação e descarte do lodo. In: ANDREOLI, C. V.; FERNANDES, F.; SPERLING, M. (Org.). Lodos de esgoto: tratamento e disposição final. Belo Horizonte: Departamento de Engenharia Sanitária e Ambiental - UFMG; Companhia de Saneamento do Paraná, 2001. p. 397-422. (Princípios do tratamento biológico de águas residuárias, 6).

GODOY, L. C. A logística na destinação do lodo de esgoto. Revista Científica On-line, São Paulo, v.2, n.1, p.12, 2013. Disponível em: < http://migre.me/qmam6> Acesso em: 18 mar. 2015.

GONÇALVES, R. F.; SPERLING, M. Lodo de esgotos: características e produção. In: ANDREOLI, C. V.; FERNANDES, F.; SPERLING, M. (Org.). Lodos de esgoto: tratamento e disposição final. Belo Horizonte: Departamento de Engenharia Sanitária e Ambiental - UFMG; Companhia de Saneamento do Paraná, 2001. cap. 2, p. 17-68. (Princípios do tratamento biológico de águas residuárias, 6).

JORDÃO, E. P.; PÊSSOA, C. A. Aproveitamento e Destino Final do Lodo. In: JORDÃO, E. P.; PÊSSOA, C. A. Tratamento de Esgotos Domésticos. 6a ed. ABES: Rio de Janeiro, 2011, cap. 18, p. 449-465.

MATTA, M. E. M. Índice de perigo para subsidiar a aplicação de lodo de esgoto em solo agrícola. Tese (Doutorado em Ciências) - Faculdade de Medicina da Universidade de São Paulo, São Paulo, 2011, 113 p. Disponível em: <http://migre.me/qmaA7> Acesso em: 30 abr. 2015.

RODRIGUES, I. O.; SILVA, M. G. Dinâmica populacional e rede coletora de esgoto. In: INSTITUTO BRASILEIRO DE GEOGRAFIA E ESTATÍSTICA. Atlas de saneamento 2011. Ministério do Planejamento, Orçamento e Gestão Instituto Brasileiro de Geografia e Estatística - IBGE Diretoria de Geociências. Rio de Janeiro, 2011. cap. 10.

SANTOS, E. R. Caracterização química, microbiológica e toxicidade do lodo de esgoto da Estação Mangueira, Pernambuco, Brasil. Dissertação (Mestrado em Desenvolvimento em Processos Ambientais) Universidade Católica de Pernambuco, Recife, 2009, 68 p. Disponível em: <http://migre.me/qmaCZ> Acesso em: 16 mai. 2015.

Persp. Online: exatas \& eng., Campos dos Goytacazes, 17 (07) 80 - 87 - 2017

seer.perspectivasonline.com.br 
SANTOS, H. F. Normatização para o uso agrícola dos biossólidos no exterior e no Brasil. In: ANDREOLI, C. V.; FERNANDES, F.; SPERLING, M. (Org.) Belo Horizonte: Departamento de Engenharia Sanitária e Ambiental - UFMG; Companhia de Saneamento do Paraná, 2001. cap.10. (Princípios do tratamento biológico de águas residuárias, 6).

USEPA - United States Environmental Protection Agency (2000). Introduction: Need for partnerships. In: USEPA. Guide to field storage of biosolids and other organic by-products used in agriculture and for soil resource management. EPA/832-B-00-007.Washington, 137 p., cap. 1.

Persp. Online: exatas \& eng., Campos dos Goytacazes, 17 (07) 80 - 87 - 2017 seer.perspectivasonline.com.br 